\title{
QUANDO O COTIDIANO PEDE ESPAÇO NA ESCOLA, O PROJETO DA FEIRA DE CIÊNCIAS "VIDA EM SOCIEDADE" SE CONCRETIZA
}

\author{
Science education through teaching projects: the case of "Life in society"
}

\author{
Nora Ney Santos Barcelos ${ }^{1}$ \\ Giuliano Buzá Jacobucci ${ }^{2}$ \\ Daniela Franco Carvalho Jacobucci ${ }^{3}$
}

Resumo: Este trabalho traz apontamentos sobre as Feiras de Ciências no contexto histórico do ensino de ciências no Brasil e do ensino por projetos. Na intenção de investigar uma Feira de Ciências realizada em uma escola estadual de Uberlândia, MG, com base no ensino por projetos e a partir de uma parceria escola-universidade, desenvolvemos esta pesquisa com objetivo de analisar a construção coletiva de uma proposta diferenciada de Feira de Ciências, sua respectiva avaliação e a implicação na formação de professores. O tema integrador definido pelos professores foi "Vida em sociedade", com dez temas relacionados. A avaliação da Feira foi desenvolvida por alunos, professores, pesquisadora e estagiários universitários, com discussão sobre os pontos evidenciados pelos envolvidos. De forma geral, o projeto foi compreendido positivamente pelos alunos e professores, mas a forma como os professores percebem o ensino por projetos e a Feira de Ciências determina o envolvimento dos mesmos na elaboração do evento.

Palavras-chave: Feira de Ciências. Ensino por projetos. Trabalho coletivo.

Abstract: This work provides information on Science Fairs within the historical context of science education in Brazil and of education through project work. A Science Fair was investigated in a state school in Uberlândia - Brazil, on the basis of education through projects and with a School-University partnership. The research aims to analyze the collective construction of a differentiated proposal of a Science Fair, its respective evaluation and the implications for teacher training. The common factor defined by the teachers was Life in Society, with ten related subjects. The evaluation of the Fair was developed by the students, teachers, researcher and trainees, with a discussion on the points evidenced by the group involved. In a general way, the project was positively understood by the students and teachers, but the way the teachers perceived education by projects and the Science Fair determines their involvement in the development of the event.

Keywords: Fair of sciences. Education by projects. Collective work.

${ }^{1}$ Bióloga. Doutora em Educação. Docente, Instituto de Biologia, Universidade Federal de Uberlândia (IB/

UFU). Uberlândia, MG, Brasil. <noraney@netsite.com.br>

${ }^{2}$ Biólogo. Doutor em Ecologia. Docente, IB/UFU. Uberlândia, MG, Brasil. <jacobucci@inbio.ufu.br>

${ }^{3}$ Bióloga. Doutora em Educação. Docente, IB/UFU. Uberlândia, MG, Brasil. < danielafcj@inbio.ufu.br>

\footnotetext{
${ }^{1}$ Instituto de Biologia, Universidade Federal de Uberlândia Campus Umuarama, Bloco 4C, sala 223

Uberlândia, $\mathrm{MG}$

$38.400-902$
} 
Barcelos, N. N. S.; Jacobucci, G. B.; Jacobucci, D. F. C.

\section{Percorrendo o caminho da história}

A década de 1960 foi marcada pela tradução e adaptação de projetos norte-americanos para o Ensino de Ciências e pelo treinamento ${ }^{4}$ de professores para a aplicação desses projetos. Havia a preocupação para que houvesse ensino e pesquisa nas escolas experimentais, como os colégios de aplicação e os ginásios vocacionais e, para tanto, ocorreu a produção de textos, material de laboratório e outros recursos didáticos, bem como o treinamento de professores visando a mudança de currículos na rede pública. Os projetos utilizavam o método científico experimental pela redescoberta para o ensino de ciências, o qual era incentivado durante o treinamento de professores. Para demonstrar a exequibilidade dos mesmos em sala de aula, os docentes executavam os experimentos, simulando a forma como seus alunos fariam. Segundo Gouvêa (1992), os cursos de treinamento para professores, juntamente com alguns eventos iniciados no período, como as feiras de ciências, clubes de ciências, congresso jovem cientista e concurso cientista do amanhã, contribuíram para reforçar a introdução do método experimental no ensino de ciências nas escolas.

Ao iniciarem no Brasil, na década de 1960, as primeiras Feiras Escolares serviram para familiarizar os alunos e a comunidade escolar com os materiais existentes nos laboratórios, antes quase inacessíveis e, portanto, desconhecidos na prática pedagógica (MANCUSO, 2000).

É importante destacar que, desde os anos 1950 e mais fortemente no final da década de 1960, foram difundidas diferentes abordagens de ensino, baseadas na problematização e realização de experimentos para o ensino de ciências. No início dos anos 1970, teve início o Projeto Nacional para Melhoria do Ensino de Ciências (PNMEC), uma vez que as ações realizadas na década anterior não resultaram em modificações significativas no ensino de ciências. Ainda havia a adaptação de projetos estrangeiros, mas o PNMEC, mesmo com o apoio financeiro do MEC/USAID ${ }^{5}$, previa a elaboração de novos materiais e propostas para o ensino de ciências, com ampliação da produção de programas nacionais. As ações estabelecidas nessa época reforçaram a importância do método experimental por meio da valorização dos materiais didáticos, sobretudo dos kits de laboratório (MAURÍCIO, 1992; GASPAR, 1993; HAMBURGER, 2001).

Na década de 1980, os professores de Ciências, especialmente do Ensino Fundamental, foram convidados a participar de cursos de treinamento, que se destinavam a introduzir, no currículo, Aulas de Laboratório e Feiras de Ciências como forma de viabilizar o método científico (GOUVÊA, 1992). Essas propostas alternativas pareciam aproximar professores e alunos de quem fazia Ciência, uma vez que a realização das atividades envolvia observação de fenômenos e experimentação. Embora nesses momentos o aluno tivesse a oportunidade de realizar as atividades, criava-se uma dicotomia entre o ensino teórico e transmissivo na sala de aula e o ensino prático no Laboratório e na Feira de Ciências.

\footnotetext{
" O termo "treinamento" foi amplamente utilizado até o final da década de 1980 em virtude do Modelo Clássico de formação continuada de professores. Para um maior aprofundamento, vide Candau (1997) e Jacobucci (2006).

${ }^{5}$ Acordo entre o Ministério da Educação (MEC) e a United States Agency for International Development USAID.
} 
Quando o cotidiano pede espaço na escola ...

Durante os anos 1980, por influência da formação dos professores de Ciências com base no paradigma da Racionalidade Técnica, numa concepção positivista da formação (DAMIS, 2003; PALMA FILHO e ALVES, 2003; PEREIRA, 2000; CANDAU, 1982), o modelo funcionalista do conhecimento repercutiu não apenas nas aulas teóricas de Ciências, mas também nas aulas de Laboratório e nas Feiras de Ciências. Algo comum era a repetição, pelos alunos, nas Feiras de Ciências, de experimentos descritos nos livros didáticos ou daqueles desenvolvidos no Laboratório (FRACALANZA, 1993). Apesar dessa prática reprodutivista, a apresentação dos trabalhos para a sociedade por intermédio da Feira de Ciências constituía uma oportunidade única para os alunos ocuparem o lugar de sujeito-falante e entusiasmado com a Ciência, algo não vivenciado em sala de aula. Mesmo a Feira de Ciências sendo praticada na lógica da receita, e não da ação criativa, esse evento era considerado excelente pelos alunos, em função de ser uma forma diferente de aprender.

Nessa época, a Feira de Ciências passou a ser a marca da escola inovadora, devido à proposta alternativa que mostrava que os alunos também podiam aprender fora do espaço da sala de aula e, até mesmo, da escola, quando se utilizavam praças públicas e locais de convivência comunitária para a realização desse tipo de evento.

E os professores, que lugar ocupavam na Feira de Ciências? Geralmente, apenas os professores de Ciências e Biologia participavam do evento, ajudando a definir os temas, a marcar a data da apresentação e visitando alguns trabalhos dos alunos. Na maioria das vezes, transferiam a responsabilidade de orientar, avaliar e escolher os melhores trabalhos aos professores da Universidade, que frequentemente colaboravam com a escola. Dessa forma, os professores não conseguiam perceber os conteúdos aprendidos por cada aluno durante a Feira. Não discutiam os erros cometidos durante a apresentação, porque o evento terminava justamente com a apresentação e, no outro dia, não se falava mais sobre a Feira. Além disso, como os professores não assistiam às apresentações de todos os alunos, multiplicavam-se os conflitos na avaliação. Essa prática avaliativa desconsiderava totalmente o processo, a subjetividade e o contexto da realização do trabalho. Diante desses impasses, alguns professores passaram a exigir um relatório, porém sem orientação prévia (BARCELOS et al., 2004).

Com a introdução de novas visões sobre a formação dos professores de Ciências, baseadas no paradigma da Epistemologia da Prática divulgado no final dos anos 1980 e início da década de 1990, isoladamente nos cursos de capacitação ou fazendo parte dos programas de formação continuada, aos poucos, os professores começaram a modificar a ação pedagógica em sala de aula, permitindo a interferência dos alunos durante suas explicações. Nesse período, foi possível observar uma tendência de mudança do nome Feira de Ciências para Feira Científico-cultural. Lentamente, outras disciplinas como Geografia, História e Física, além de Ciências e Biologia, foram assumindo o cenário dessa nova modalidade de Feira, porém, a metodologia de preparação, apresentação e avaliação continuou sendo a mesma de antes.

\section{O ensino por projetos e as Feiras de Ciências}

O debate sobre currículo integrado e interdisciplinar está em aberto. Há autores que argumentam contra essa proposta e muitos outros a favor. Para Doll (1997), um currículo construtivo é aquele que emerge por meio da ação e interação dos participantes; ele não é 
estabelecido antecipadamente, a não ser em termos amplos e gerais. Assim, quanto mais rico for o currículo, mais haverá pontos de interseção, conexões construídas e mais profundo será o seu significado.

O pesquisador Hernández (1998) afirma que o papel do currículo integrado é educar para compreender, e que interpretar vem a ser manifestar explicitamente essa compreensão. $\mathrm{Na}$ mesma linha de pensamento, Santomé (1998) coloca que, em geral, poucos estudantes são capazes de vislumbrar algo que permita integrar conteúdos ou o trabalho das diferentes disciplinas. A coerência com que se afirma que são planejados os conteúdos dos sistemas educacionais dificilmente é visível pelos alunos e, algumas vezes, até mesmo para os professores, independentemente do nível educacional. Além disso, os alunos não transferem espontaneamente para outras disciplinas aquilo que aprendem em uma disciplina, nem utilizam esse conhecimento para enfrentar situações reais.

A pesquisadora Girotto (2005) defende que uma via metodológica alternativa, como o ensino por projetos, pode corroborar e superar o processo de ensinar e aprender fragmentado, disciplinar, descontextualizado, unilateral e direcionador, que se constata na maioria das escolas. Essa autora aponta que a expressão Pedagogia de Projetos se relaciona à corrente teórica da francesa Josette Jolibert e do espanhol Fernando Hernández (HERNÁNDEZ e VENTURA, 2000; HERNÁNDEZ, 1998; JOLIBERT, 1994), baseada no princípio de que, ao participar de um projeto, o aluno está envolvido em uma experiência educativa em que o processo de construção de conhecimento está integrado às práticas vividas, desenvolvendo uma atividade complexa, na qual se apropria, ao mesmo tempo, de um determinado objeto de conhecimento cultural, formando-se como sujeito cultural.

O ensino por projetos implica um olhar diferente do docente em relação ao aluno, sobre seu próprio trabalho e sobre o rendimento escolar. Para Barcelos (2001), o ensino por projetos envolve planejar, desenvolver e avaliar a(s) atividade(s), condições essas que podem ser estruturadas em três fases:

1 Problematização e Sensibilização - Nessa fase, os alunos e professores percebem, de forma conjunta, que existe algo no cotidiano que pode ser explorado, e, dessa forma, discutem sobre as necessidades e os motivos para a realização de um projeto. Ocorre a definição do tema geral do projeto - e dos subtemas quando couber -, dos objetivos, das disciplinas e dos professores que devem estar envolvidos no projeto, além das datas para preparação e apresentação das atividades previstas.

2 Viabilização e Implementação - Nessa etapa, os problemas a serem estudados pelos grupos ou pela classe são definidos. Há uma busca pela metodologia de trabalho mais adequada para resolver o problema do tema proposto, com definição de procedimentos e estratégias viáveis.

3 Consolidação e Avaliação - Nessa fase ocorre o desenvolvimento das ações planejadas e de outras que não foram inicialmente planejadas, a organização dos dados para apresentação à comunidade escolar, e, finalmente, a elaboração de um relatório final que deve contemplar a autoavaliação dos envolvidos e a avaliação do projeto pelos alunos, professores e demais participantes.

As Feiras de Ciências se constituem palco para um trabalho baseado no ensino por projetos. Por ser um evento institucional, implica a mobilização de muitas pessoas da comunidade escolar e de outros espaços para sua realização. Como qualquer outra atividade de ensi- 
Quando o cotidiano pede espaço na escola ...

no-aprendizagem que envolve criatividade e investigação na busca de soluções para uma situação problematizadora, a realização de uma Feira Científico-cultural requer um pré-projeto, visto que um evento dessa natureza depende de uma série de medidas e providências que devem ser pré-programadas.

\section{A pesquisa}

$\mathrm{Na}$ intenção de investigar uma Feira de Ciências realizada em 1999 em uma escola pública estadual de Uberlândia - MG, com base no ensino por projetos e a partir de uma parceria Escola-Universidade, desenvolvemos o presente trabalho com o objetivo de analisar a construção coletiva com a comunidade escolar de uma proposta diferenciada de Feira de Ciências e sua respectiva avaliação.

O presente trabalho se caracteriza como uma pesquisa qualitativa do tipo observação participante e se constitui como um estudo de caso (LAVILLE e DIONNE, 1999; LÜDKE e ANDRÉ, 1986), definido por Megid Neto (2001) como um estudo que focaliza indivíduos ou organizações educacionais, utilizando preferencialmente técnicas e métodos característicos da abordagem qualitativa, e que considera um grande número de dimensões e variáveis a serem observadas e inter-relacionadas, para a descrição de uma realidade ampla.

A pesquisadora da Universidade Federal de Uberlândia, no papel de assessora pedagógica voluntária (APV) na referida escola, desenvolvia o acompanhamento da construção coletiva do projeto da Feira de Ciências e sugeria ideias para o mesmo. Como pesquisadora, atuou registrando suas memórias de todo o processo, em caderno de campo, que serviram de base para essa pesquisa.

A pesquisa foi desenvolvida em três eixos. O eixo "Construção coletiva de um projeto de Feira de Ciências" apresenta uma descrição de todas as etapas envolvidas no planejamento e elaboração do projeto da Feira de Ciências investigada, com base no caderno de campo da APV. O eixo "Avaliação da Feira de Ciências" apresenta a análise dos dados obtidos por meio de questionário semiestruturado para a coleta de opiniões de alunos e professores orientadores da Feira de Ciências, com base em Alves-Mazzotti e Gewandsznajder (2002). O eixo "Discussão da Feira de Ciências como projeto" apresenta argumentação teórica na temática do ensino por projetos e as Feiras de Ciências.

\section{Construção coletiva de um projeto de Feira de Ciências}

Em outubro de 1999, professores do Ensino Fundamental de uma Escola Estadual do município de Uberlândia - MG estavam vivenciando os efeitos colaterais das Reformas Educacionais da época que previam mudanças curriculares nos conteúdos e na metodologia de ensino e avaliação. Por motivos nem sempre explícitos, a comunidade escolar passava por uma síndrome de mal-estar docente ${ }^{6}$, caracterizada pela desmotivação.

\footnotetext{
${ }^{6}$ Para mais informações sobre esse tema, vide Carlotto (2002).
} 
O único discurso vigente era de que a Educação precisava se aproximar do cotidiano, reeducar o desejo e a vontade de professores e alunos, e que a escola precisava mudar o currículo, exercer autonomia e inovar na avaliação.

Nesse contexto, a pesquisadora que já participava há um ano das atividades da escola como APV, passou a vivenciar dois níveis de interação na escola: na mediação ou promoção de condições para alguns professores modificarem suas concepções, posturas e crenças para trabalharem com ações educativas coletivas e integradas; e na reflexão sobre a vida real da escola com acadêmicos do curso de Licenciatura em Ciências Biológicas da Universidade Federal de Uberlândia, que desenvolviam estágio supervisionado na época (BARCELOS, 2001).

$\mathrm{Na}$ tentativa de constituir um campo de pesquisa para seu Mestrado focalizando a formação continuada de professores, a pesquisadora propôs a realização de uma Feira de Ciências diferente, com fases bem definidas de planejamento, preparação, apresentação e avaliação, cujo desenvolvimento seria feito de forma conjunta com professores e alunos.

Como a escola não trabalhava com Módulos ${ }^{7}$, a APV tinha muita dificuldade para conversar com os 16 professores, e, assim, passou a utilizar os momentos de convívio na sala de professores, nos intervalos entre as aulas ou nas "janelas", para trocar ideias com o grupo de docentes e instituir discussões sobre o projeto da Feira de Ciências. A partir das experiências dos professores e das orientações orais, rápidas e possíveis, desenvolvidas pela APV sobre ensino por projetos, foram estabelecidos novos objetivos e princípios metodológicos para o desenvolvimento da Feira. Para os professores daquela escola, essa proposta não era uma novidade, pois eles já haviam vivenciado uma experiência por temática/classe subsidiada por um projeto externo, chamado Bem Ti Verde ${ }^{8}$, o qual representou para a APV um ponto de partida favorável para a proposta da Feira de Ciências. Os alunos do curso de Licenciatura em Ciências Biológicas da UFU também participaram da elaboração do projeto da Feira de Ciências, juntamente com os professores.

A reação dos professores foi começar questionando sobre por onde começar, quando o projeto deveria acontecer, em quantas aulas e qual seria sua duração. Outras colocações também foram feitas: "Qual o lado prático disso? Os alunos vão ter algum resultado com isso? Eu acredito que esse projeto épara fazer alguma mudança". De outras conversas surgiram frases muito significativas, como: "Então, é uma proposta coletiva. Será que os alunos têm paciência para ouvir o colega falar? [...] Isso é muito bonito, teoricamente funciona, mas para uma sala de vinte alunos e não para quarenta".

Como resultado desse processo de discussão inicial sobre a Feira de Ciências, foi estabelecido que o objetivo da Feira seria levar os alunos de cada classe a constituírem grupos de trabalho para a realização de uma meta comum: a de envolver todos os alunos com conteúdos de várias disciplinas na busca da construção de conhecimentos diversificados. De forma mais específica, os professores colocaram os seguintes objetivos para a Feira:

\footnotetext{
${ }^{7}$ Tempo obrigatório de reunião que acontece por área ou individualmente, a critério das escolas da Rede Estadual de Ensino do Estado de Minas Gerais.

${ }^{8}$ O projeto Bem Ti Verde do IBAMA (Instituto Brasileiro do Meio Ambiente e dos Recursos Naturais Renováveis) foi uma atividade pioneira na Área de Educação Ambiental realizada em Uberlândia, Minas Gerais, entre 1997 e 1999. Fonte: http://www.radiobras.gov.br/ct/1997/materia_310197_7.htm
} 
Quando o cotidiano pede espaço na escola ...

. Divulgar os resultados das atividades escolares desenvolvidas durante as aulas;

- Integrar a comunidade à escola;

- Despertar e/ou desenvolver o gosto pela pesquisa e experimentação;

- Desenvolver a criatividade e o espírito crítico dos alunos;

. Formar hábitos e atitudes sociais e o senso de responsabilidade;

- Desenvolver habilidades específicas, interesses e competências.

A partir dessas observações, os professores explicitaram, nas discussões casuais do grupo docente da escola, a necessidade de trabalharem juntamente com os alunos a formação de atitudes de respeito, solidariedade, justiça e diálogo, bem como os valores de dignidade e autonomia.

Após a definição dos objetivos mais gerais pelo grupo de professores, estes passaram a discutir a proposta da Feira de Ciências com os alunos durante as aulas, alguns de forma mais intensiva, outros de forma mais esporádica. Os princípios descritos a seguir foram destacados como fundamentais para o bom funcionamento do evento:

a) Modificação do nome do evento de Feira de Ciências para Feira Científico-Cultural, no intuito de envolver professores de outras disciplinas, e não somente de Ciências e Biologia;

b) Proposição de temas mais amplos para permitir a liberdade de criação dos alunos, e da classe como um todo, o que poderia evitar trabalhos individualizados ou realizados por pessoas externas à escola (profissionais convidados);

c) Definição inicial dos temas do evento pelos professores, e, depois, por classe, ou de forma conjunta com os alunos, procurando adequá-los ao interesse dos alunos e ao programa curricular. Nesse aspecto, foi evidenciado que a escolha do tema de forma conjunta com os alunos, apesar de ser democrática, exigiria um tempo maior para a própria definição e preparação posterior da atividade;

d) Os alunos de cada classe deveriam ter funções específicas na Feira - expositores, assessores ou expectadores, respeitando a sua opção, a partir de suas próprias dificuldades e possibilidades;

e) O resultado da avaliação do relatório final deveria ser atribuído a todas as disciplinas envolvidas;

f) Cada classe deveria ser orientada por dois ou mais professores (professores orientadores), sendo que, durante a apresentação, pelo menos um desses professores deveria acompanhar a turma;

g) $\mathrm{Na}$ data da apresentação, cada sala de aula deveria ser ambientada para um determinado tema, sendo que dois grupos poderiam trabalhar com o mesmo tema. O primeiro grupo deveria apresentar o trabalho até o $3^{\circ}$ horário, enquanto o segundo grupo deveria expor nos últimos horários;

h) Os assessores e expectadores deveriam conhecer os outros trabalhos por meio de um rodízio de troca de sala em ciclos de vinte minutos, para permitir que todos os alunos tivessem tempo para visitar as demais atividades;

i) Os professores orientadores deveriam acompanhar os alunos durante as trocas de sala, e, assim, teriam a oportunidade de conhecer os outros trabalhos;

j) O último horário deveria ser disponibilizado para visitação livre, inclusive pela sociedade. 
O projeto da Feira de Ciências foi elaborado com base no ensino por projetos, levando em consideração os princípios tidos como fundamentais pelos professores. Foi definido que o evento seria desenvolvido em três etapas: 1 Pré-projeto - definição do tema, dos objetivos e do planejamento; 2 Desenvolvimento - apresentação prévia aos professores orientadores e dos trabalhos na Feira; e 3 Avaliação - elaboração do relatório final com avaliação pessoal e do evento.

A APV propôs aos professores que os alunos escolhessem os temas, a partir de uma lista que seria elaborada pelos professores. No entanto, à medida que os professores foram percebendo que a sua participação seria imprescindível para o bom desempenho e aprendizado dos alunos, optaram pela decisão de que os professores, e não os alunos, escolheriam os temas. Para tanto, os professores utilizaram os seguintes critérios: disponibilidade para orientação, relação dos temas com os conteúdos curriculares de suas próprias disciplinas e idade dos alunos.

O tema integrador da Feira de Ciências definido pelos professores foi Vida em sociedade e, de forma relacionada com esse tópico, foram escolhidos dez temas: A arte e a vida; $\mathrm{O}$ esporte e a vida; Educação para a paz e cidadania; Meio ambiente; Parque do Sabiá ${ }^{9}$; Educação, saúde e sexualidade; Culinária, educação alimentar e etiqueta social; A escola que somos e que queremos; Brasil 500 anos; e Globalização da economia. Os temas foram distribuídos por classes ( $5^{\mathrm{a}}$ a $8^{\mathrm{a}}$ séries) de acordo com elementos curriculares comuns à série, e com exceção dos temas "Educação, saúde e sexualidade" e "Globalização da economia", os demais foram distribuídos de tal forma que duas salas realizaram atividades na mesma temática.

As funções dos alunos na realização da Feira foram divididas em três categorias: expositores, assessores ou expectadores. Os alunos expositores foram responsáveis pelo planejamento do projeto, juntamente com os assessores, e também pela apresentação formal do trabalho durante a realização do evento. Os assessores, além de auxiliarem na preparação do projeto, foram responsáveis pelo suporte aos expositores durante a Feira. Os expectadores tinham a função de visitar todos os estandes de exposição das salas durante a Feira, independentemente da série. Essa diferenciação das funções discentes na Feira de Ciências foi uma tentativa de respeitar a vontade e o interesse de participação de cada aluno.

A orientação do trabalho a ser apresentado na Feira por cada classe, desde o projeto até a avaliação do evento, ficou sob a responsabilidade dos professores orientadores. Em média, os alunos tiveram de dois a três meses para a realização das três etapas da Feira: projeto, desenvolvimento e avaliação. Na semana anterior à realização do evento, o grupo de expositores apresentou o planejamento (Pré-projeto) aos professores orientadores. Esse planejamento foi constituído pelo objetivo da Feira e do tema a ser trabalhado, os procedimentos que seriam utilizados na exposição e as referências bibliográficas utilizadas. A apresentação prévia dos projetos aos professores orientadores destinava-se a observação geral das propostas de trabalho, atendimento específico aos alunos expositores e preparação para a montagem dos estandes na sala de aula.

${ }^{9}$ Parque municipal em Uberlândia, MG, muito frequentado pelos moradores da cidade. 
Quando o cotidiano pede espaço na escola ...

A apresentação dos trabalhos na Feira foi realizada com a supervisão de, pelo menos, um professor orientador, com o papel de proferir elogios, intervenções e orientações aos alunos expositores e visitantes. Conforme solicitação dos alunos, no último horário, a sala foi aberta para visitação dos colegas de classe e de outras classes, além dos pais visitantes. Essa visita livre gerou alguns transtornos logísticos, como: salas que ficaram sem expositores, grupos que desmontaram a exposição para evitar danos ao material e outros grupos que não receberam visitantes.

A avaliação do desempenho e das atitudes dos alunos ocorreu uma semana após a realização do evento. Os alunos foram reorientados a elaborar um relatório final, de acordo com os seguintes tópicos: Introdução - descrição do objetivo geral da feira e dos temas expostos e/ou assistidos; Apresentação e desenvolvimento do evento como um todo - registro do que foi apresentado na Feira, com descrição do que aprendeu com a exposição; Conclusão comentário geral sobre o evento, com uma avaliação da Feira, do desempenho do grupo e de si mesmo; Sugestões; Elogios e Homenagens.

\section{Avaliação da Feira de Ciências}

Após a construção coletiva do projeto da Feira de Ciências e realização do evento, a pesquisadora propôs uma avaliação geral do evento pelos envolvidos, sendo: alunos, professores orientadores, estagiários universitários e a própria pesquisadora. A coleta de opiniões de alunos e professores orientadores foi baseada em questionário semiestruturado (ALVESMAZZOTTI e GEWANDSZNAJDER, 2002).

Para os alunos, foi solicitado o preenchimento de um questionário com cinco perguntas, que deveriam ser respondidas usando frases curtas e/ou palavras-chave do tipo "interessante", "curioso", dentre outras. Os respondentes foram sorteados por sala/série. A sala sorteada foi a $6^{a} E$, que trabalhou o tema "Educação, Saúde e Sexualidade". Dessa forma, 26 alunos se prontificaram a responder o questionário.

Para os professores, foi requerido o preenchimento de um questionário com três perguntas: 1 Como você se sentiu desde que iniciamos as discussões sobre o projeto da Feira de Ciências? 2 Como foi o comportamento dos alunos que ficaram sob sua orientação? 3 Qual a sua opinião sobre a nova proposta metodológica utilizada nessa Feira e o que pode ser modificado na próxima? Apenas cinco professores orientadores se prontificaram a responder as questões, sendo os responsáveis pelos seguintes temas e respectivas disciplinas: "Brasil 500 anos" - professor de geografia, "Parque do Sabiá" e "A arte e a vida" - professor de português, "A escola que queremos" - professor de ciências, e "O esporte e a vida" - professor de educação física e professor de inglês.

O depoimento dos estagiários sobre a avaliação do projeto da Feira de Ciências foi livre e voluntário, na forma de um texto-síntese coletivo. A avaliação da pesquisadora foi registrada no formato narrativo. 
Barcelos, N. N. S.; Jacobucci, G. B.; Jacobucci, D. F. C.

\section{Avaliação da Feira de Ciências pelos alunos}

As questões propostas aos alunos e as respostas mais frequentes estão descritas no Quadro 1. As palavras-chave foram mantidas sem distinção de gênero.

Quadro 1. Avaliação do projeto da Feira de Ciências pelos alunos.

\begin{tabular}{|l|l|}
\hline \multicolumn{1}{|c|}{ Questões } & \multicolumn{1}{c|}{ Respostas dos alunos } \\
\hline Como você se sentiu quando recebeu o tema? & $\begin{array}{l}\text { Imaturo, legal, inseguro, muito bem, assustado, surpreso, } \\
\text { interessado, envergonhado. }\end{array}$ \\
\hline $\begin{array}{l}\text { Como foi preparar e apresentar o tema, em } \\
\text { relação aos aspectos de curiosidade, conquista, } \\
\text { aprendizado e dificuldades? }\end{array}$ & $\begin{array}{l}\text { Divertido, difícil, legal, curioso, constrangedor, importante, } \\
\text { interessante, massa }{ }^{10} \text {, fantástico, criativo, educativo. }\end{array}$ \\
\hline $\begin{array}{l}\text { Como você se sente hoje, em relação ao que } \\
\text { aprendeu? }\end{array}$ & $\begin{array}{l}\text { Mais informado, falo com naturalidade, que somos } \\
\text { semelhantes, consigo agora me expressar melhor, adorei. }\end{array}$ \\
\hline $\begin{array}{l}\text { Como foi trabalhar em grupo e o que você achou } \\
\text { que foi bom para a sua formação como } \\
\text { indivíduo? }\end{array}$ & $\begin{array}{l}\text { Todos ajudaram uns aos outros, as pessoas são diferentes, } \\
\text { ficamos amigos, temos que conviver com as pessoas, } \\
\text { aprendemos mais. }\end{array}$ \\
\hline $\begin{array}{l}\text { O que você achou da forma de preparação e e } \\
\text { apresentação dos trabalhos? }\end{array}$ & $\begin{array}{l}\text { Diferente, ótimo, muita conversa, o aluno deveria escolher o } \\
\text { tema, maior tempo para preparação, cumprir o tempo da } \\
\text { apresentação, mais teatro, menos apresentação simples. }\end{array}$ \\
\hline
\end{tabular}

${ }^{10}$ Similar a legal ou bacana.

De forma geral, o projeto da Feira de Ciências foi compreendido positivamente pelos alunos, uma vez que a maioria das palavras-chave utilizadas para responder às questões remete a uma conotação de aprovação.

Apesar das palavras-chave "difícil" e "constrangedor" evidenciarem a dificuldade que os alunos tiveram para preparar e apresentar o tema, as demais respostas comprovam que a atividade foi aprazível.

As respostas para as questões que pretendiam focalizar o sentimento dos alunos em relação à própria aprendizagem e ao trabalho em grupo mostram dois aspectos distintos: um, de que todos são semelhantes, provavelmente em relação às dificuldades encontradas para trabalhar o tema e à aprendizagem; outro, que as pessoas são diferentes, talvez em função do trabalho em grupo requerer atitudes de tolerância, respeito mútuo e solidariedade para a realização da atividade.

Em relação à metodologia de ensino por projetos adotada para a realização da Feira, os alunos viram pontos satisfatórios, descritos por meio das palavras-chave "diferente" e "ótimo", no entanto, as reflexões sobre a forma de preparação e apresentação dos trabalhos foram destacadas de maneira crítica. 
Quando o cotidiano pede espaço na escola ...

\section{Avaliação da Feira de Ciências pelos professores orientadores}

Em relação às discussões sobre o projeto da Feira de Ciências, a maioria dos professores expressa consentimento, conforme evidenciam os depoimentos.

"Aconteceu de forma positiva, pois os alunos se sentem bem tendo a liberdade de trabalbo. Houve uma euforia, correria em busca de atingir o objetivo, desperton a criatividade". (Professor de geografia)

"Um grande entusiasmo de todos, principalmente dos alunos. O tema despertou interesse e o trabalho de campo foi feito com muita curiosidade, pois as perguntas que surgiram antes despertaram para assuntos que ainda não haviam sido explorados, como o objetivo do parque [Parque do Sabiá], sua área, as espécies de animais, de onde vieram e como chegaram ao parque. Considerei a Feira de grande valor para o crescimento intelectual e social do aluno, como também um fator de integração entre os professores, alunos e direção da escola". (Professor de português)

"Interessada e comprometida". (Professor de educação física)

"Tudo que envolve atividade extra-classe não deixa de ser incentivo para o aluno. Por isso, apoiei e incentivei meus alunos durante todos os preparativos da Feira, no que foi possivel”. (Professor de inglês)

Um dos professores mostrou uma visão contrária aos demais professores:

"Com certo receio. A receptividade dos colegas [professores] não foi total. Muitas turmas não tiveram o apoio devido". (Professor de Ciências)

O envolvimento de professores em grupos de trabalho com assessoria externa nem sempre tem sido um sucesso. Várias experiências de constituição de grupos de professores em coletivos de trabalho para a reformulação de currículos estão relatadas no livro "Educação em Ciências: produção de currículos e formação de professores” (MORAES e MANCUSO, 2004). Há relatos de professores participantes dos grupos que, de forma interessada, se envolvem com seus pares e tornam possível um ambiente de discussão sobre diversas questões que promovem a concretização de mudanças no processo de ensino e transformações significativas na escola e na comunidade local. Já em alguns grupos não há integração entre os pares e os pesquisadores, o que gera um desconforto na relação, tornando muito difícil a discussão de problemas da prática docente, a leitura de textos e a abertura a novas propostas de ensino.

Em nosso caso, houve superação das expectativas. Parece-nos que um dos elementos indicadores foi a forma de assessoria pedagógica proposta e desenvolvida pela APV, que levava em consideração a história de vida dos professores envolvidos em um ambiente de recíproca colaboração.

Em relação ao comportamento dos alunos, alguns professores acharam boa a participação discente e outros, apenas satisfatória. 
Barcelos, N. N. S.; Jacobucci, G. B.; Jacobucci, D. F. C.

"Eu faltei em algumas aulas e o tema que estava orientando foi mudado, com isso não foi possivel acompanhar de uma forma melhor. Faltou também de quem estava organizando me avisar o dia dos trabalhos. De forma geral considero positivo o trabalho como um todo". (Professor de geografia)

"O comportamento foi o melhor que eles puderam (sic!). Algumas reuniōes com muitas idéias, todos falando ao mesmo tempo, devendo-se a isso o grande interesse do tema. [...] Vale ressaltar a grande iniciativa dos meus alunos de buscarem sozinhos o material, a pesquisa e os patrocinadores. Penso que esta experiência trouxe aos alunos um aprendizado de grande importância para a convivência em grupo, paciência com os colegas, iniciativa". (Professor de inglês)

"Exatamente como eu esperava. De inicio sentiram-se perdidos e sem saberem o que fazer. A partir das orientações, foram surgindo idéias. [...] Porém, não posso deixar de expressar que todos os alunos, de um modo geral, são quase totalmente despreparados sobre pesquisa, talvez pela pouca intensidade com que acontecem". (Professor de inglês)

"A participação foi razoável. Faltou motivação, vontade dos alunos". (Professor de ciências)

"Considerei satisfatória, não percebi que houve interesse por parte deles, só houve um questionamento”. (Professor de educação física)

É importante destacar desses depoimentos dois aspectos em relação à postura dos professores: 1 do professor que, na figura de professor orientador, se mostra alheio às atividades que estão sendo desenvolvidas no projeto, assumindo um papel de expectador passivo diante da falta de interesse dos alunos e que deve ser informado por terceiros sobre o que está ocorrendo; 2 do professor orientador participante, que, mesmo frente às dificuldades do projeto, se envolve com os alunos para a solução conjunta dos problemas.

Quando questionados sobre a nova proposta metodológica utilizada nessa Feira, os professores apontaram aspectos bem trabalhados na Feira e outros que deveriam ser modificados em eventos futuros. Um dos aspectos foi a realização da Feira em época de provas, que acabou desviando a atenção dos alunos e prejudicando tanto a realização do evento como as provas. Outro ponto destacado foi a falta de tempo para a preparação das atividades, visto que muitos alunos deixaram de assistir às aulas para desenvolver o trabalho. Houve um destaque para a forma de avaliação, visto que os professores consideraram complexa a avaliação pelo relatório final dos alunos.

"Quanto à forma de avaliação foi complicado avaliar em um mesmo nivel expositor, assessor e expectador, pois os expositores trabalharam muito mais". (Professor de português) 
Quando o cotidiano pede espaço na escola ...

"A metodologia foi ótima. Minha sugestão para a próxima é que a avaliação seja feita em forma de teste ou questionário e que os temas sejam escolbidos pelos alunos". (Professor de educação física)

"Quanto à forma de apresentação e avaliação, considero-as razoáveis, podemos mudá-las para algo melhor e mais proveitoso, porém estou sem sugestão agora”. (Professor de inglês)

Embora o professor de educação física tenha afirmado que a metodologia de projeto da Feira de Ciências foi ótima, nenhum outro professor mencionou, no depoimento, a questão do método de ensino por projetos. Assim, não é possível inferir se os professores compreenderam a proposta da metodologia de projeto utilizada na Feira, e nem mesmo se esses professores conseguiram relacionar o desenvolvimento da Feira como um todo, desde sua pré-preparação até o desenvolvimento e avaliação, a um projeto.

\section{Avaliação da Feira de Ciências pelos estagiários universitários}

Para os estagiários, que acompanharam todo o processo de desenvolvimento do projeto tanto do lado dos professores orientadores como dos alunos, a metodologia empregada foi adequada à proposta original de desenvolver a Feira de Ciências como um projeto.

"Esse novo modelo de evento científico-cultural proporcionou além de uma melhor organização didática, uma maior interação dos alunos com seus colegas e professores. Embora a diretora tenha afirmado que os alunos não estavam se mostrando interessados em realizar a próxima Feira nesse modelo, preferindo o modelo convencional de apresentação dos trabalhos [repetição de experimentos do livro didático ou do laboratório]. Consideramos que a nova modalidade de apresentação dos temas garante maior participação e uma aprendizagem mais significativa, entretanto ainda existem alguns problemas a serem solucionados, tais como: tumulto no momento do rodízio dos alunos, dificuldade dos alunos em romper com uma crença tradicional de Feira, falta de apoio dos professores que pode ser pela insegurança diante da inovação. A forma de solucionar tal impasse seria promover novamente o evento, para refletir na ação possiveis mudanças". (Texto-síntese coletivo dos estagiários universitários)

O destaque dos estagiários para a questão da reflexão dos professores na ação, ou seja, durante e logo após a realização do evento é uma consideração válida. No entanto, para que seja possível essa reflexão coletiva é imprescindível que a coordenação geral esteja atenta a essa necessidade. Somente com a definição prévia de que a possibilidade de avaliar as atividades durante o desenvolvimento das mesmas é uma etapa importante do projeto, visto que poderá promover modificações imediatas, haverá tempo disponível para essa reflexão. 
Barcelos, N. N. S.; Jacobucci, G. B.; Jacobucci, D. F. C.

\section{Avaliação da Feira de Ciências pela pesquisadora}

As observações da pesquisadora em relação ao planejamento e desenvolvimento das atividades da Feira são similares às já destacadas pelos alunos e professores.

"A idéia inovadora foi um desafio para toda a comunidade escolar. Os alunos, em principio, não gostaram do tema ter sido escolbido pelos professores, porém, as classes que foram orientadas satisfatoriamente, não reclamaram mais sobre isso. Um fator que causou reclamação por parte dos alunos foi que eles tiveram apenas quinze dias para o desenvolvimento da Feira. [...] Além do que, a fase de apresentação dos trabalhos aconteceu na véspera das provas bimestrais finais".

A pesquisadora destaca a importância do coletivo na elaboração do projeto e de como o estímulo dos alunos desencadeou a participação dos professores no evento.

"Mesmo com todas as dificuldades, considerei riquissima essa experiência de ensino. Muitos professores entraram no movimento da Feira para dar conta da demanda e do dinamismo dos alunos. Enfim, os temas do cotidiano e a nova metodologia da Feira contribuiram com os professores, fazendo com que eles se esquecessem, um pouco, do fantasma da avaliação. Eles deram mais sentido social aos trabalhos, envolvendo decisões e ações de muitas pessoas em conjunto. Foi uma ação educativa que conseguiu mobilizar a comunidade escolar em torno de um projeto".

Sobre a mobilização dos professores, a pesquisadora acredita que:

"Foi mais um trabalho coletivo, de certa forma inovador, que mobilizou muitos professores, um trabalho intelectual, no qual podia constatar o ensino dos três conteúdos da reforma [Reforma Escolar]: procedimento, atitude e conbecimento de todas as matérias, embora a proposta não tenha mobilizado todos os professores. Alguns deles não conseguiam ter esse olhar, fazer uma avaliação inovadora considerando tais aspectos, pois ainda estavam presos apenas aos conteúdos disciplinares. [...] Percebi que quando existe um projeto coletivo, eles [professores] se envolvem por um tempo curto, pois querem resultados imediatos e não gostam de substituir suas aulas regulares por atividades do projeto. Enfim, não conseguem trabalhar com duas ou mais propostas pedagógicas simultaneamente, numa mesma disciplina. Na opinião deles é como se o ensino por projeto não incorporasse os conteúdos que são para eles obrigatórios e curriculares, ou se sentem ameaçados com a abertura que o projeto oferece aos alunos".

A forma como os professores percebem o ensino por projetos e a Feira de Ciências determina o envolvimento dos mesmos na elaboração do evento. Quando os professores não vislumbram a possibilidade de substituir ou ampliar os conteúdos curriculares a serem trabalhados em sala de aula pelas atividades da Feira, ocorre um conflito de interesses entre o que o aluno quer conhecer mais para expor na Feira e o que o professor quer abordar em classe. 
Quando o cotidiano pede espaço na escola ...

Cria-se um cabo-de-guerra ${ }^{11}$ fictício, no qual de um lado fica o professor com sua autoridade e poder avaliativo, e de outro, os alunos, que desejam participar integralmente da Feira. Dessa forma, a negociação dos temas e dos conteúdos a serem desenvolvidos para a mostra no evento tem que ser totalmente coerente com a proposta do professor e da disciplina sob sua responsabilidade.

\section{Feira de Ciências como projeto}

O ensino por projetos, por ser uma proposta teórico-metodológica alternativa, ressurgida na década de 1990, ainda não está sendo compreendida em sua totalidade pelos professores. Um exemplo dessa lacuna entre o referencial teórico e as atividades desenvolvidas nas escolas com base nesse referencial é a dissertação de mestrado de Márcio Evangelista dos Santos. O autor investigou como os professores de Ensino Médio, licenciados em Química, das escolas da rede pública estadual de Goiás, encaram e praticam a educação por projetos, a relação com o processo de ensino e aprendizagem, e se suas concepções são coerentes com as práticas. Para esses professores, os projetos são acontecimentos, tais como as Feiras Culturais ou de Ciências. Embora os professores afirmem trabalhar com ensino por projetos, não fazem a distinção entre ensino por projetos de ensino a partir de situação problema, trabalho e aulas extraclasse (SANTOS, 2006).

É necessário aprofundar o estudo nessa temática, visto que a dificuldade dos professores em conceituar o ensino por projetos pode ocultar um desconhecimento sobre o que realmente é um projeto. E, quando o professor não tem segurança no trabalho que deve desenvolver, geralmente opta por não realizá-lo.

Embora seja um evento comumente realizado no ambiente escolar, a produção acadêmica sobre as Feiras de Ciências ainda é escassa, e pouco é discutido sobre o papel dos professores e as percepções dos mesmos sobre o evento. Por outro lado, as publicações nessa área mostram vertentes de socialização e multiplicidade pedagógicas capazes de enriquecer o processo de ensino-aprendizagem. Um exemplo é o trabalho de Hoernig (2004), que aponta os eventos informais, como a Feira de Ciências, Mostra Científica ou Mostra Cultural, como oportunidades de: proporcionar a todos os seus participantes a vivência de processos cognitivos de caráter interdisciplinar; promover a Alfabetização e a Educação Científica; possibilitar o intercâmbio entre as escolas e as comunidades, e contribuir com a formação integral do aluno.

Nessa mesma linha, Farias (2006) acredita que as Feiras de Ciências podem contribuir para a socialização e troca de experiências de ensino-aprendizagem-conhecimentos com a comunidade, possibilitando uma ampliação da visão de mundo dos participantes, expositores e visitantes da Feira, permitindo a divulgação dos resultados das pesquisas, troca de experiências entre os pares, como forma de validação do conhecimento.

${ }^{11}$ Jogo em que duas equipes puxam em direções opostas as pontas de uma corda. 
Barcelos, N. N. S.; Jacobucci, G. B.; Jacobucci, D. F. C.

Com possibilidades tão ricas de vivência coletiva e democratização do conhecimento científico, as Feiras de Ciências precisam ser reconstruídas pela comunidade escolar, e a metodologia do ensino por projeto pode ser uma alternativa curricular, quando compreendida e aceita pelos professores. Para a pesquisadora Marilda Shuvartz (1995), é importante manter as Feiras de Ciências como espaço de Educação Científica, o que obriga um repensar desses programas educativos, a serem refletidos, estruturados e implementados por meio de parcerias na perspectiva da relação Ciência, Tecnologia e Sociedade.

A inclusão de temas transversais propostos pelos Parâmetros Curriculares Nacionais - PCNs (BRASIL, 1998), como "Educação e Sexualidade" e "Educação Alimentar" na Feira de Ciências, amplia o cenário do evento, desvinculando a proposta atual da Feira CientíficoCultural da feira científica das décadas passadas. Nesse contexto, Wanderley (1999) afirma que as Feiras de Ciências que são organizadas num contexto mais flexível e mais amplo, com a incorporação de novos elementos ligados, sobretudo, à formação estética e social dos alunos, propiciam uma multiplicidade de aspectos pedagógicos que ultrapassam a perspectiva anterior de investigação científica, realizada à luz do método científico.

Em relação à avaliação do desempenho dos alunos no evento, há muito a ser discutido, visto que a utilização exclusiva do relatório final elaborado pelos discentes não foi considerada uma alternativa válida por alguns professores. Há apenas um trabalho que engloba a dimensão avaliativa das Feiras de Ciências, no qual o autor (MANCUSO, 1993) sugere uma nova proposta de avaliação do desempenho dos alunos em Feiras de Ciências, a avaliação participativa, que elimina o poder decisório incontestável das comissões julgadoras, substituindo-as pelas comissões de avaliação, onde estão presentes os próprios alunos expositores, seus orientadores, outros professores e até representantes da comunidade.

\section{Considerações finais}

A realização de uma Feira de Ciências de acordo com a proposta do ensino por projetos envolve etapas fundamentais de preparação, desenvolvimento e avaliação, assim como qualquer projeto de pesquisa ou de ensino.

No caso específico descrito nesse trabalho, mesmo com o envolvimento dos professores, apoio da direção da escola e discussão prévia e ao longo do processo do projeto, algumas falas evidenciam lacunas na realização da Feira. Embora mudanças efetivas e significativas tenham sido percebidas na prática, provavelmente se os professores tivessem investido mais tempo para pensar o evento junto com a APV, desde o início do projeto até sua execução e avaliação, muito dos pontos criticados pela comunidade escolar poderiam ter sido modificados e os resultados poderiam ter sido melhores.

Da mesma forma, se houvesse possibilidade de um encontro permanente com os professores da escola e a assessora, em horários reservados para o projeto, poderia haver discussões sobre as concepções que os envolvidos possuem de Feira de Ciências e ensino por projetos, e essa discussão poderia ocorrer previamente à decisão de realizar a Feira. Assim, os professores poderiam se posicionar a respeito do projeto e optar em participar ou não. 
Quando o cotidiano pede espaço na escola ...

A experiência mostrou que ainda é importante, no ambiente escolar, a presença de "um outro", o assessor pedagógico real, e não virtual, para ajudar a consolidar, de fato, o significado que a realidade das inovações impõem para a comunidade escolar.

Os professores mostraram disposição para derrubar as paredes que isolavam os educadores, os conteúdos e, consequentemente, as disciplinas, rompendo, assim, a rotina cotidiana das áreas convencionais, desde a inclusão do projeto Vida em sociedade na prática. Está em aberto a possibilidade de surgimento de outros projetos nessa abordagem, uma forma de operacionalizar mudanças didáticas e inovação na avaliação para atender novas demandas sociais e culturais.

A metodologia de ensino por projetos estruturante da Feira de Ciências constitui uma oportunidade ímpar para a formação continuada de professores, pois envolve a sensibilização dos participantes, o planejamento da proposta, a implementação e a avaliação do trabalho, sendo que, em todas essas etapas, os professores se deparam com desafios que precisam ser discutidos coletivamente.

A Feira de Ciências é uma forma de a escola criar oportunidades para os alunos integrarem conteúdos de diferentes disciplinas curriculares, além de abrir espaço para o estudo e trabalho de conteúdos extracurriculares, ocultos no currículo. Ao ser concebido como um projeto, o evento passa a ser uma das etapas a serem realizadas, e provavelmente não a mais importante, visto que as dimensões sociais e culturais das relações entre os envolvidos no projeto fortalecem vínculos afetivos e a formação cidadã.

\section{Referências}

ALVES-MAZZOTTI, A. J.; GEWANDSZNAJDER, F. O método nas ciências naturais e sociais: pesquisa quantitativa e qualitativa. São Paulo: Pioneira Thompson Learning, 2002.

BARCELOS, N. N. S. A prática e os saberes docentes na voz de professores do Ensino Fundamental na travessia das reformas educacionais. 2001. 143f. Dissertação (Mestrado em Educação) - Faculdade de Educação, Universidade de São Paulo, São Paulo, 2001.

. et al. Feira de Ciências: nosso olhar para as diferentes abordagens de realização. In: ENCONTRO PERSPECTIVAS DO ENSINO DE BIOLOGIA, 9., 2004, Campinas. Caderno de Programação e Resumos... Campinas: Sociedade Brasileira de Ensino de Biologia, 2004. p. 47.

CANDAU, V. M. F. Formação continuada de professores: tendências atuais. In: Magistério: construção cotidiana. Petrópolis: Vozes, 1997. p. 51-68.

A formação de educadores: uma perspectiva multidimensional. Em Aberto, Brasília, v. 1, n. 8, p. 19-21, 1982. 
Barcelos, N. N. S.; Jacobucci, G. B.; Jacobucci, D. F. C.

CARLOT'TO, M. S. A Síndrome de burnout e o trabalho docente. Psicologia em Estudo, Maringá, v. 7, n. 1, p. 21-29, 2002.

DAMIS, O. T. Formação pedagógica do profissional da educação no Brasil: uma perspectiva de análise. In: VEIGA, I. P. A.; AMARAL, A. L. (Orgs.). Formação de professores, políticas e debates. Campinas: Papirus, 2003. p. 97-130.

DOLL, J. W. Currículo: uma perspectiva pós-moderna. Porto Alegre: Artmed, 1997.

FARIAS, L. N. Feiras de Ciências como oportunidades de (re)construção do conhecimento pela pesquisa. 2006. 89f. Dissertação (Mestrado em Educação em Ciências e Matemáticas) - Núcleo Pedagógico de Apoio ao Desenvolvimento Científico, Universidade Federal do Pará, Belém, 2006.

FRACALANZA, H. O que sabemos sobre os livros didáticos para o ensino de Ciências no Brasil. 1993. 1054f. Tese (Doutorado em Educação) - Faculdade de Educação, Universidade Estadual de Campinas, Campinas, 1993.

GASPAR, A. Museus e Centros de Ciências: conceituação e proposta de um referencial teórico. 1993. 100f. Tese (Doutorado em Educação) - Faculdade de Educação, Universidade de São Paulo, São Paulo, 1993.

GIROTTO, C. G. G. S. A (re)significação do ensinar-e-aprender: a pedagogia de projetos em contexto. Núcleos de Ensino da Unesp, São Paulo, v. 1. n. 1, p. 87-106, 2005.

GOUVEIA, M. S. F. Cursos de Ciências para professores do $\mathbf{1}^{\mathbf{0}}$ grau: elementos para uma política de formação continuada. 1992. 409f. Tese (Doutorado em Educação) Faculdade de Educação, Universidade Estadual de Campinas, Campinas, 1992.

HAMBURGER, E. W. A popularização da ciência no Brasil. In: CRESTANA, S. (Coord.); HAMBURGER, E. W.; SILVA, D. M.; MASCARENHAS, S. (Orgs.). Educação para a Ciência: curso para treinamento em Centros e Museus de Ciência. São Paulo: Livraria da Física, 2001. p. 31-40.

HERNÀNDEZ, F. Transgressão e mudança na educação: os projetos de trabalho. Porto Alegre: Artmed, 1998.

HERNÁNDEZ, F.; VENTURA, M. A organização do currículo por projetos de trabalho: o conhecimento é um caleidoscópio. Porto Alegre: Artes Médicas, 2000.

HOERNIG, B. A. Feira de Ciências: uma estratégia para promover a iniciação à educação científica. 2004. 114f. Dissertação (Mestrado em Ensino de Ciências e Matemática) Universidade Luterana do Brasil, Porto Alegre, 2004.

JACOBUCCI, D. F. C. A formação continuada de professores em Centros e Museus de Ciências no Brasil. 2006. 268f. Tese (Doutorado em Educação) - Faculdade de Educação, Universidade Estadual de Campinas, Campinas, 2006.

JOLIBERT, J. Formando crianças leitoras de texto. Porto Alegre: Artes Médicas, 1994. 
Quando o cotidiano pede espaço na escola ...

LAVILLE, C.; DIONNE, J. A construção do saber: manual de metodologia da pesquisa em ciências humanas. Porto Alegre: Artes Médicas Sul, 1999.

LÜDKE, H. A. L. M.; ANDRÉ, M. Pesquisa em educação: abordagens qualitativas. São Paulo: EPU, 1986.

MANCUSO, R. Feira de Ciências: produção estudantil, avaliação, conseqüências. Contexto Educativo Revista Digital de Educación y Nuevas Tecnologías, Buenos Aires, v. 6, n. 1, p. 1-5, 2000.

A evolução do programa de Feiras de Ciências do Rio Grande do Sul: avaliação tradicional e avaliação participativa. 1993. 334f. Dissertação (Mestrado em Educação) - Universidade Federal de Santa Catarina, Florianópolis, 1993.

MAURÍCIO, L. A. Centro de Ciências: origens e desenvolvimento - uma relação sobre seu papel e possibilidade dentro do contexto educacional. 1992. 146f. Dissertação (Mestrado em Educação) - Instituto de Física/Faculdade de Educação, Universidade de São Paulo, São Paulo, 1992.

MEGID NETO, J. Elaboração de projetos técnicos de pesquisa. Campinas: Faculdade de Educação, 2001.

MORAES, R.; MANCUSO, R. (Orgs.). Educação em ciências: produção de currículos e formação de professores. Ijuí: Editora Unijuí, 2004.

PALMA FILHO, J. C.; ALVES, M. L. Formação continuada: memórias. In: BARBOSA, R. L. L. (Org.). Formação de professores: desafios e perspectivas. São Paulo: Editora Unesp, 2003. p. 279-296.

PEREIRA, J. E. D. Formação de professores: pesquisa, representações e poder. Belo Horizonte: Autêntica, 2000.

SANTOMÉ, J. T. Globalização e interdisciplinaridade: o currículo integrado. Porto Alegre: Artes Médicas, 1998.

SANTOS, M. E. O ensino por projetos em Química. 2006. 94f. Dissertação (Mestrado em Educação em Química) - Instituto de Química, Universidade Federal de Goiás, Goiânia, 2006

SHUVARTZ, M. As Feiras Estaduais de Ciências: em busca do pedagógico. 1995. $147 \mathrm{f}$. Dissertação (Mestrado em Educação) - Faculdade de Educação, Universidade Federal de Goiás, Goiânia, 1995.

WANDERLEY, E. C. Feiras de Ciências enquanto espaço pedagógico para aprendizagens múltiplas. 1999. 190f. Dissertação (Mestrado em Educação Tecnológica) Centro Federal de Educação Tecnológica de Minas Gerais, Belo Horizonte, 1999.

Artigo recebido em julho de 2009 e aceito em março de 2010. 